\title{
Royal College of Psychiatrists' Archives
}

\section{The search for accommodation}

\author{
Margaret Harcourt Williams
}

When Samuel Hitch and his five colleagues agreed to form the Association of Medical Officers of Asylums and Hospitals for the Insane in 1841 it probably never occurred to them that it would grow into an organisation needing its own headquarters. The first mention of a permanent headquarters is in the minutes of the 1864 annual meeting when the President, Dr Munro, suggested: "If we could get thus into bricks and mortar, and have a more solid existence than at present, that would help to establish us very much". However, the meeting decided against this on the grounds that it would make the Association "a strictly metropolitan one". The question was discussed at intervals until 1893 when the Association, by then called the Medico Psychological Association (MPA), began to lease space from the Medical Society of London at 11 Chandos Street.

The Association made a rather limited arrangement with the Medical Society of London. A rent was paid for the use of 11 Chandos Street as an official address, for a room for meetings, for a desk in the library from which to deal with correspondence, and for one bookcase. It seems that the use of a room for meetings was more important at that time than office accommodation. Most of the secretarial work and all the editorial and financial matters were dealt with in the hospitals where the Secretary, Editor and Treasurer worked and this may be why few nineteenth and early twentieth century archives of the Association have survived.

The MPA, which became the Royal Medico Psychological Association (RMPA) in 1926. moved to BMA House in Tavistock Square in the same year. It was hoped that here the RMPA would have rooms of its own - but these did not become available, and so, in 1932, the RMPA returned to Chandos Street, this time with a room for an office and a paid secretary.

A series of agreements for extra rooms in the archives show how over the years the work of the RMPA, the staff and the need for accommodation increased. In the early 1960s a move to the Royal College of Physicians' new building in Regent's
Park was considered but instead the RMPA moved from Chandos Street to the Royal Society of Medicine's Chandos House.

In the early $1970 \mathrm{~s}$, the change in status to a Royal College, the increase in administrative staff and the end of the Chandos House lease led to the decision to find a permanent headquarters. Various options were suggested, including moving to a property adjoining the Royal College of Physicians, moving outside London, building on a new site in London and renting or buying within London. A number of properties were considered. These included St Peter's Hospital in Henrietta Street "an attractive brick building", Queen Mary's Maternity Home, Hampstead "solidly built in Neo-Georgian style", the Moorfields Hospital Highgate Annexe "a very respectable residential area" and the Royal Victoria Patriotic Asylum in Wandsworth, originally "built to house 300 orphaned daughters of the brave Crimea dead".

However, in 1974 the College moved to 17 Belgrave Square. There was a lot of work to be done when the College moved in and it soon became clear that there were opportunities for extending the building. It was extended at the back and a fourth floor was built to provide additional office space. The archives include specifications, correspondence and architects' plans for the extensions and alterations.

In 1997 an extensive refurbishment of the formal rooms was begun with the aim of meeting both the College's practical needs and enhancing the period detail of its property - this refurbishment is still in progress.

These notes have been written using minutes of Association meetings, correspondence and memos from Appeals Committee files and notes and plans relating to alterations to 17 Belgrave Square. All this material is in the College archives. Please ask the Archivist if you have any questions about the archives.

Margaret Harcourt Williams, Archivist, Royal College of Psychiatrists, 17 Belgrave Square, London SW1X 8PG 